\title{
Effect of thermo-oxidation on loss of plasticizers, on crystalline features and on properties in a metallocene isotactic polypropylene
}

\author{
Enrique Blázquez-Blázquez, Rosa Barranco-García, María L. Cerrada*, Ernesto Pérez \\ Instituto de Ciencia y Tecnología de Polímeros (ICTP-CSIC), Juan de la Cierva 3, 28006 Madrid, Spain
}

Corresponding Author: mlcerrada@ictp.csic.es

\begin{abstract}
Incorporation of a low content of several plasticizers into a metallocene isotactic polypropylene (iPP) has been performed in order to learn about their stability and performance by the action of a thermo-oxidative degradation treatment at $95{ }^{\circ} \mathrm{C}$ for different times. Comparison with the behavior exhibited by the material with di(2-ethylhexyl) phthalate (DEHP) is established for a feasible replacement of its use for contributing to environmental and human health preservation. Dependence of these aggressive degrading conditions on plasticizer loss is analyzed as well as elucidation of degradation influence on the iPP crystalline characteristics. The results show that chemical changes associated with this degradation process hinder formation of the orthorhombic $y$ crystalline lattice and postpone the overall crystallization capability. Accordingly, the final features in the film surface and the mechanical response are significantly affected by degradation time. The TOTM plasticizer can be considered an excellent candidate for DEHP substitution.
\end{abstract}

Keywords: Polypropylene; plasticizer; thermo-oxidation; $a$ and y polymorphs; crystallization delay. 


\section{Introduction}

Plasticizers are indispensable in many applications. They are employed as softeners for rigid materials since they lead to reduction of viscosity as well as increase of flexibility. They are not chemically bound to the plastic materials and, therefore, they can leach, migrate or evaporate into indoor air and atmosphere, foodstuff, liquids, or other materials. Consequently, they are present in the environment and can be incorporated into humans and animals through ingestion, inhalation, and dermal contact [1-5] so that they are classified as environmental pollutants with a strong influence on the human health.

Di-butyl phthalate (DBP) and Di(2-ethylhexyl) phthalate (DEHP) have been the phthalic acid esters with the largest production volume worldwide. In the last decades, the possible human health effects of phthalate plasticizers have been intensely discussed and some of those compounds have been classified as endocrine disruptors $[3,6,7]$ and potential carcinogens $[3,8]$. Based on these findings, Directive 2005/84/EC established restrictions on the use and marketing of certain dangerous substances and on preparation of formulations (phthalates in toys and childcare articles). Therefore, some phthalates have been classified since 2008 as reprotoxic substances of class $1 \mathrm{~B}$ by the European Union due to their toxicity. Specifically, the use of DEHP in medical devices for administration/removal of drugs or biological liquids has been restricted by the European Directive 2007/47/CE. For that reason, they have been proposed to be substituted by non-phthalate compounds like acetyl tributyl citrate (ATBC), diisononyl 1,2-cyclohexanedicarboxylic acid (DINCH), di(2-ethylhexyl) terephthalate (DEHT) or trioctyl trimellitate (TOTM) in many applications. These non-phthalate substances have shown advantageous toxicological profiles and the toxic effects on human health during their release from polymers to the environment are strongly reduced. Due to the ongoing substitution process and considering new regulatory requirements, plasticizer substitutes have subsequently been added to the list of substances of interest. Several studies have been conducted to evaluate the migration behavior in poly(vinyl chloride) (PVC) medical devices that include these plasticizers of new generation [9] and to analyze their presence in different environments and in humans [10-14] in order to replace the use of DEHP. The ATBC incorporation has been also examined in other polymeric systems, like poly(lactic acid) and poly(hydroxybutyrate), among others [15-17].

An additional concern is related to the use of PVC in applications as containers either for food or for medical products. Severe health risks can exist, mainly in the latest devices with prolonged interaction body fluids (like disposable blood bags) or tissues, since PVC can slowly liberate free chlorine, chlorine species and dioxins along its usage. Thus, its substitution would minimize exposure to potential toxicities. Accordingly, investigations have been promoted in manufacturing of single-use 
packaging materials that not release toxic substances during their medical and food handling. Polypropylene (PP) is proposed as an alternative to PVC, among other polymers. Suitable mechanical properties, including flexibility, are an important issue in these applications and incorporation of plasticizers is required. Evaluation of the effect of DBP or DEHP on PP has been previously described in literature [7]. Nevertheless, unlike other polymers [10-17], there is, to our knowledge, no exhaustive study of the addition into PP of these safer plasticizers to simultaneously substitute the phthalate plasticizers and the PVC in this contact application with food or in that medical-clinical one. Therefore, the aim of this research is to proceed to the incorporation of a small amount of different less toxic plasticizers into an isotactic metallocene polypropylene (iPP) to evaluate its loss as a function of time by the action of thermo-oxidative treatment at $95^{\circ} \mathrm{C}$, and to comprehensively understand how degradation and plasticizer consumption affect the chemical details in the IPP, its crystalline characteristics, the features on surface of the film and the mechanical response. Distinct plasticizers are investigated to analyze which of them could be the best candidate for the replacement of phthalate compounds and features of the resultant materials based on PP are examined to learn about the feasible substitution of PVC by PP. The thermo-oxidation at $95{ }^{\circ} \mathrm{C}$ has been chosen because the final materials are frequently sterilized at high temperatures and during their shelf life can be heated by action of microwaves. Moreover, it provides an accelerated approach to learn how these substances are lost and the consequences of such consumption. For that, maintenance of the additive after the thermal treatment in the samples is estimated from extraction by Soxhlet and analysis using gas chromatography-mass spectroscopy (GC-MS); chemical changes involved in the iPP during the process are detected by Fourier transform infrared spectroscopy coupled with an attenuated total reflectance device (ATR-FTIR); variations in the crystalline phase transitions are assessed by differential scanning calorimetry (DSC) and real-time variable-temperature Wide Angle X-ray Diffraction (WAXD) synchrotron experiments; features of the roughness at the film surface are studied by optical profilometry; and the mechanical characteristics are evaluated by microhardness measurements.

\section{Experimental part}

\section{Materials}

A commercially available metallocene-catalyzed isotactic polypropylene (Metocene HM562P: melt flow index of $15 \mathrm{~g} / 10 \mathrm{~min}$, ISO 1133, kindly supplied as pellets by Lyondell Basell) was selected in this work as polymeric matrix.

Different plasticizers of non-phthalate nature were used: ATBC (acetyl tributyl citrate), CAS 7790-7; DEHT (di(2-ethylhexyl) terephthalate, CAS 6422-86-2; DINCH (di-isononyl-cyclohexane-1,2- 
dicarboxylate), CAS 166412-78-8; and, TOTM (trioctyl trimellitate), CAS 3319-31-1. Moreover, DEHP (diethylhexyl phthalate), CAS 117-81-7, was also evaluated as a plasticizer of phthalic chemical origin for comparative reasons. Their chemical structures are detailed together with boiling temperature $\left(T_{b}\right)$ and molecular weight (MW) in the Scheme 1. The 5CB ([1,1'-biphenyl]-4-carbonitrile, 4'-pentyl-), CAS 40817-08-1, was employed as internal reference in the GC-MS measurements. Standards with purity equal or greater than $98.0 \%$ were purchased from Sigma-Aldrich (Spain), except for DINCH that was acquired from Oxchem (USA).

Scheme 1. Chemical structures, boiling temperature $\left(T_{b}\right)$ and molecular weight $(M W)$ of the different plasticizers.

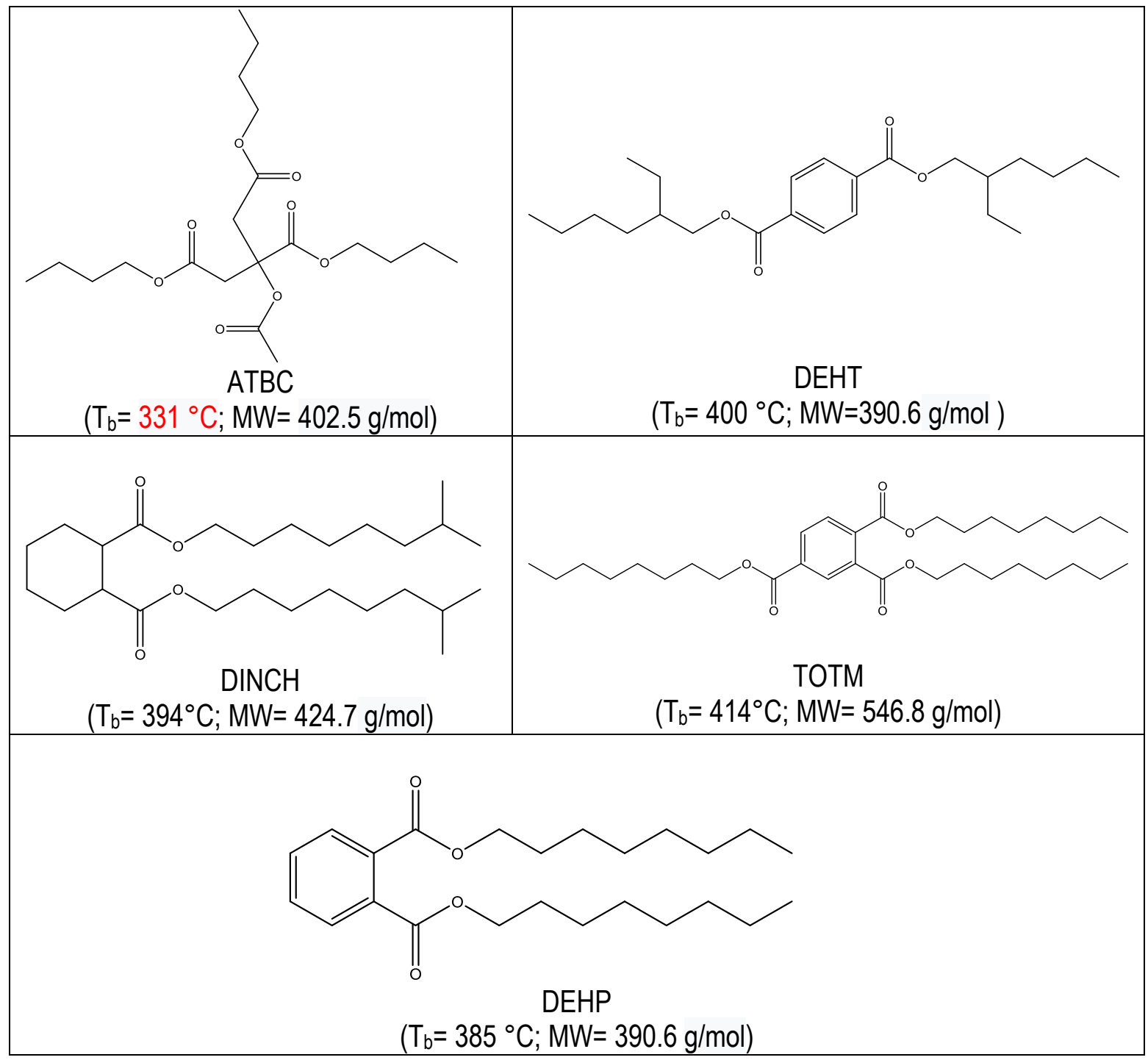

Incorporation of additives and film preparation

The different selected plasticizers were added to the homopolymer in a percentage of $2 \%$ by 
weight. These blends (homopolymer plus additive) were obtained by melt extrusion in a co-rotating twinscrew microextruder Rondol with a length-to-diameter ratio 20:1. A screw temperature profile of 115, $170,180,185$ and $190^{\circ} \mathrm{C}$ was used from the hopper to the die. Then, films with a thickness around 200 $\mu \mathrm{m}$ were processed by compression molding at $190^{\circ} \mathrm{C}$ and at 25 bar for 3 minutes in a hot-plate Collin press (200x200 model). A relatively fast cooling, at a rate of around $80{ }^{\circ} \mathrm{C} / \mathrm{min}$, was applied from the melt to room temperature between plates under pressure ( 25 bar). This thermal treatment is similar to those applied at industrial scale. Samples were labeled as: PP for the neat iPP; PP-ATBC, PP-DEHT, PP-DINCH, PP-TOTM and PP-DEHP for the materials based on IPP with ATBC, DEPT, DINCH, TOTM and DEHP plasticizer, respectively.

Thermogravimetric analysis

Dynamic thermogravimetric experiments (TGA) were performed from $40^{\circ} \mathrm{C}$ up to $800{ }^{\circ} \mathrm{C}$ in a Q500 equipment of TA Instruments under nitrogen atmosphere at a heating rate of $10{ }^{\circ} \mathrm{C} / \mathrm{min}$. Samples of approximately $10 \mathrm{mg}$ were used. These measurements were carried out for assessment of possible losses of plasticizers during processing, and also for analysis of their potential effect on the PP degradation.

\section{Accelerated degradation treatment}

Thermo-oxidative experiments were performed in a convection oven at $95{ }^{\circ} \mathrm{C}$ during different time periods: $0,2,4,8,10$ and 16 days, in films containing the distinct additives. For ATBC, two additional trials at 4 and 10 hours were conducted to obtain more information in the initial stages.

Analysis of additives

Samples were extracted in a Soxhlet with dichloromethane for 8 hours. The extraction solution was concentrated in a rotary evaporator. The obtained residue was transferred to a chromatographic vial and dried with a nitrogen flow. Then, it was re-dissolved in a specific volume of chloroform containing [1,1'-biphenyl]-4-carbonitrile, 4'-pentyl-, CAS 40817-08-1, as internal standard in a known concentration.

Analytical determination was carried out using a Hewlett Packard 6890 HRGC gas chromatograph equipped with an Agilent Technologies mass spectrometry detector model 5973. The separation of the compounds was performed on a DB5-HT capillary column (15 m x $250 \mu \mathrm{m}$ and 0.1 $\mu \mathrm{m})$. The carrier gas used was helium with a flow rate of $1 \mathrm{ml} / \mathrm{min}$. The electronic impact $(70 \mathrm{eV})$ was the selected type of ionization for the mass spectrometer.

The chosen chromatographic method lasted 37.5 minutes. The program started at $80{ }^{\circ} \mathrm{C}$, 
temperature was increased at a constant rate of $8{ }^{\circ} \mathrm{C} / \mathrm{min}$ up to $340{ }^{\circ} \mathrm{C}$, and was maintained for 5 minutes at that high temperature.

Fourier transform infrared spectroscopy (FTIR)

The chemical changes induced within each polypropylene-plasticizer material during its degradation at $95^{\circ} \mathrm{C}$ at the different times were studied through Fourier transform infrared spectroscopy using a total attenuated reflectance device (FTIR-ATR). Spectra were recorded on a PerkinEImer Spectrum Two spectrophotometer with a resolution of $4 \mathrm{~cm}^{-1}$.

Size exclusion chromatography

The molecular weights of selected samples were evaluated by size exclusion chromatography (SEC) at $145{ }^{\circ} \mathrm{C}$ in a Waters GPC/ 2000 equipment with both refractive index and viscosimetry detectors. A set of three columns of the PL Gel type was used with 1,2,4-trichlorobenzene as solvent. The equipment was calibrated with polystyrene standards of narrow molecular mass distributions. The average molecular weights and polydispersity index, $\mathrm{PI}$, obtained are commented in the discussion.

Differential Scanning Calorimetry (DSC)

Calorimetric analyses were performed in a TA Instruments Q100 calorimeter connected to a cooling system and calibrated with different standards. The sample weights ranged from 6 to $8 \mathrm{mg}$. A temperature interval from -65 to $200{ }^{\circ} \mathrm{C}$ was studied at a scanning rate of $20^{\circ} \mathrm{C} / \mathrm{min}$. The first melting and the crystallization processes were evaluated in detail. For the determination of the crystallinity, a value of $160 \mathrm{~J} / \mathrm{g}[18,19]$ was used as the enthalpy of fusion of a perfectly crystalline material.

$X$-ray experiments with synchrotron radiation

Real-time variable-temperature WAXD experiments were carried out with synchrotron radiation in beamline BL11-NCD at ALBA (Cerdanyola del Valles, Barcelona, Spain) at a fixed wavelength of 0.1 $\mathrm{nm}$. A Rayonix detector has been used at a distance about $19 \mathrm{~cm}$ from sample and a tilt angle of around 30 degrees. A Linkam Unit, connected to a cooling system of liquid nitrogen, was employed for the temperature control. The calibration of spacings was obtained by means of silver behenate and $\mathrm{Cr}_{2} \mathrm{O}_{3}$ standards. The initial 2D X-ray images were converted into 1D diffractograms, as function of the inverse scattering vector, $s=1 / d=2 \sin \theta / \lambda$. Film samples of around $5 \times 5 \times 0.2 \mathrm{~mm}$ were used in the synchrotron analysis.

Nuclear Magnetic Resonance

Tacticity was determined by carbon nuclear magnetic resonance analysis, ${ }^{13} \mathrm{C} N \mathrm{NM}$, from a polymeric solution in 1,1,2,2-tetrachloroethane- $d_{4}(70 \mathrm{mg} / 1 \mathrm{~mL})$ at $100{ }^{\circ} \mathrm{C}$, using a Bruker Avance 
III/500 spectrometer operating at $125.76 \mathrm{MHz}$. A minimum of 4000 scans were recorded with broad band proton decoupling, using an acquisition time of $1.3 \mathrm{~s}$ and a pulse delay of $5 \mathrm{~s}$.

Optical profilometer

Surface characteristics of the films, in terms of changes in roughness associated with the loss of plasticizers, were measured in a Z-20 True color 3D Optical Profiler (Zeta Instruments)

This equipment allows measurements of features in height or surface roughness. Average Surface Roughness (Sa) was measured, following equation 1, as the arithmetic average of the absolute values of profile height deviations recorded within the evaluation area and measured from the mean surface area, which is a horizontal plane [20]:

$$
S_{a}=\frac{1}{A_{e}} \int_{0}^{L_{y}} \int_{0}^{L_{x}} \mid z(x, y) d x d y
$$

\section{Microhardness measurements}

A Vickers indentor attached to a Leitz microhardness tester was used to perform microindentation measurements at $23^{\circ} \mathrm{C}$. A contact load of $0.98 \mathrm{~N}$ for a time of $25 \mathrm{~s}$ was employed. Microhardness, $\mathrm{MH}$, values (in MPa) were calculated according to the relationship [21]:

$$
M H=2 \sin 68^{\circ}\left(\frac{P}{d^{2}}\right) \quad \text { (Equation 2) }
$$

where $P$ (in $\mathrm{N}$ ) is the contact load and $d$ (in $\mathrm{mm}$ ) is the diagonal length of the projected indentation area. Diagonals were measured in the reflected light mode within $30 \mathrm{~s}$ of load removal, using a digital eyepiece equipped with a Leitz computer-counter-printer (RZA-DO).

\section{Results and Discussion}

Soxhlet extraction was initially performed on films processed from the pristine iPP homopolymer. The GC of this extract points out, as depicted in the upper plot of Figure 1, the presence of Irgafos 168 as additive (in a proportion of 290 ppm) and its oxidized form (Irg168 ox) at slightly higher retention time. The Irgafos 168 is a common antioxidant agent used in the iPP formulations. Other regularly added antioxidant substances, such as Irganox 1330 or Irganox 1010, are not present in this commercial polypropylene. An HPLC test was performed in this neat iPP and absence of other antioxidant compounds was confirmed. The iPP selected corresponds to a commercial grade designed to present optimal transparency and clarity during its useful life. Consequently, phenolic antioxidants were avoided due to their undesirable effect of yellowing on the final material. 
Figure 1 also shows in the lower plot the chromatograms for the extracts achieved from the distinct IPP-plasticizer materials. The internal reference used (I.S.) is clearly noticeable in all of them together with the extracting compounds characteristic for each individual plasticizer. Their retention times are rather different between them. Other remarkable aspect deduced from Figure 1 is the multiplepeak pattern observed in the PP-DINCH extract. This is because DINCH plasticizer is composed by a mixture of isomers [22].

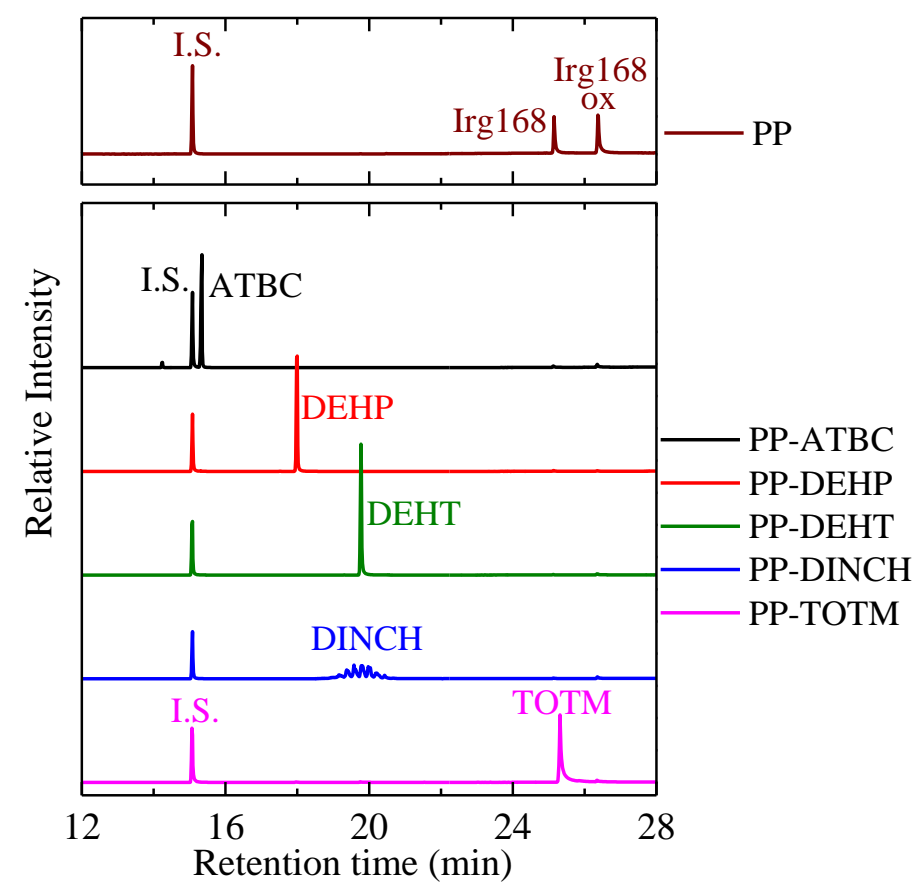

Figure 1. Comparative chromatograms for the different extracts obtained from the initial materials under analysis. From top to bottom: pristine PP, PP-ATBC, PP-DEHP, PP-DEHT, PP-DINCH and PP-TOTM.

Irgafos 168 and its oxidized form are also seen in these chromatograms (obviously with a much smaller intensity than the plasticizers, due to their lower concentration). They appear significantly minimized in relation to the extract from iPP because dilution for the chromatograms containing plasticizers is superior to that used for the iPP in order to avoid saturation.

Figure 2 represents the dependence with degradation time of remaining content for each plasticizer in the distinct iPP based films during their stay at $95^{\circ} \mathrm{C}$. Important differences are observed between them. The PP-ATBC material is the one that shows the fastest plasticizer loss rate. In fact, the ATBC amount is drastically reduced in only 10 hours. For this reason, additional degradation times of 4 and 10 hours were also used in this case. Detection content below $1 \%$ is seen in the first 48 hours and it is completely lost before 8 testing days. 
The material that incorporates the plasticizer with phthalate chemical nature, the PP-DEHP, whose replacement by other less toxic additive is desired, is the one showing the next high leakage behavior. Its content is reduced above $50 \%$ in only 4 days with respect to the initial one.

In contrast to the PP-DEHP, the PP-DEHT material, which adds the plasticizer with the nonphthalic isomeric structure, shows a considerable greater capability of remaining over time at $95{ }^{\circ} \mathrm{C}$ within the PP-DEHT films. This feature constitutes a good starting point because of its much better toxicological profile.

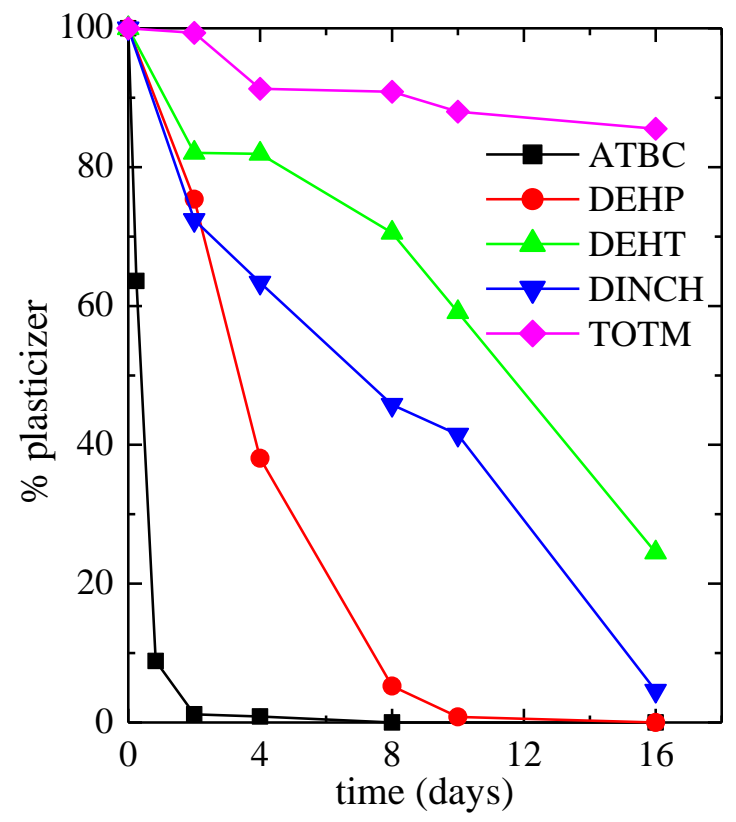

Figure 2. Dependence with degradation time at $95^{\circ} \mathrm{C}$ of the reduction in the plasticizer content for the different iPP based materials analyzed.

An intermediate behavior between that shown by the PP-DEHP and PP-DEHT is exhibited in the PP-DINCH material, as seen in Figure 2. After 8 days of permanence at $95^{\circ} \mathrm{C}$, the PP-DINCH film displays a loss of about $55 \%$ in the DINCH content.

Figure 2 also clearly displays that PP-TOTM material is the one where plasticizer remains in a very significant content at this high temperature for 16 days. Difference with the PP-DEHT, which is the next in preservation of plasticizer, is rather important: a content of around $88 \%$ of TOTM is kept versus approximately $22 \%$ of DEHT. Thus, loss of plasticizer in the PP-TOTM occurs at a rate very low. Then, similar behavior is expected in terms of structure and properties in this PP-TOTM material compared to that shown by the pristine non-plasticized iPP homopolymer. If this assumption is met, the high 
presence of TOTM under this exposure under demanding conditions seems to indicate that it is the best plasticizer option to be incorporated into the iPP.

These results are consistent with those described by Bernard et al. [9] in an earlier study in which migration was analyzed in PVC specimens with DEHP, DINCH, DEHT and TOTM plasticizers immersed at $40{ }^{\circ} \mathrm{C}$ in a simulant, consisting in an ethanol/water (50/50 v/v) mixture. A similar migration capacity for DEHP and DINCH was observed, while the TOTM migrated 20 times less. They proposed DEHT or TOTM as promising plasticizers to avoid the use of DEHP in those medical devices. A similar conclusion is reached here in the case of the iPP.

Kambia et al. [23] discussed the leaching ability of DEHP and TOTM in haemodialysis tubing when they included DEHP as unique plasticizer or in combination with TOTM. Results showed a lower migration when TOTM was added into the formulation. These data seemed to indicate that the most resistant plasticizer to be lost was the TOTM. A recent work [24] also demonstrated that when the TOTM was added to PVC, the resultant material was thermally more stable than the ones incorporating other plasticizers. These investigations induce to think that TOTM could become the safest plasticizer candidate to replace the use of the toxic DEHP.

In order to assess possible losses of plasticizer during processing, and also the potential effect of plasticizers on the iPP degradation, TGA measurements have been performed on the original samples. The results are shown in Figure 3. It can be observed that there is practically no effect on the main PP degradation, since the plasticizer is lost first (as clearly depicted in Figure 4). Anyway, a small but appreciable stability increase is visible in the case of PP-TOTM.

Figure 4 shows the comparison of the TGA curves of the pristine plasticizers (bottom) with those attained for the iPP-plasticizer materials (upper, amplification of Figure 3). It can be observed in the upper plot that the amount of lost plasticizer is close to $2 \%$, which is the original value added to the compounded iPP samples, except in the cases of PP-ATBC and PP-DEHP, where that value is somewhat smaller (close to $1.6 \%$ ). Importantly, these weight losses profiles match rather perfectly those of the pure plasticizers, as shown by the guide lines in Figure 4. On the other hand, TOTM, which presents the chemical structure with higher molecular weight, exhibits a degradation pattern at significantly higher temperature than the other plasticizers.

These TGA degradation profiles can explain, at least partially, the reduction in the plasticizer content for the different iPP based materials observed in Figure 2, which appears to be mostly due to its volatility. Evidently, possible specific interactions between iPP and the plasticizer molecules could have an additional effect. 


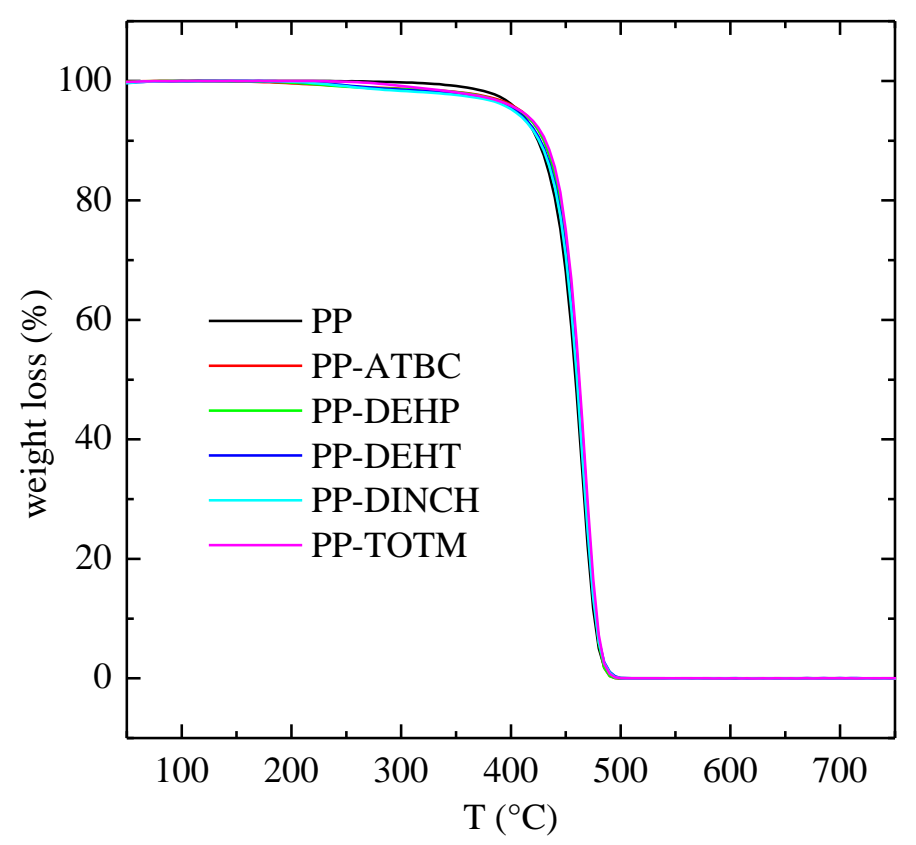

Figure 3. TGA curves for the different samples. The temperature interval from 100 to $400{ }^{\circ} \mathrm{C}$ has been amplified in Figure 4.

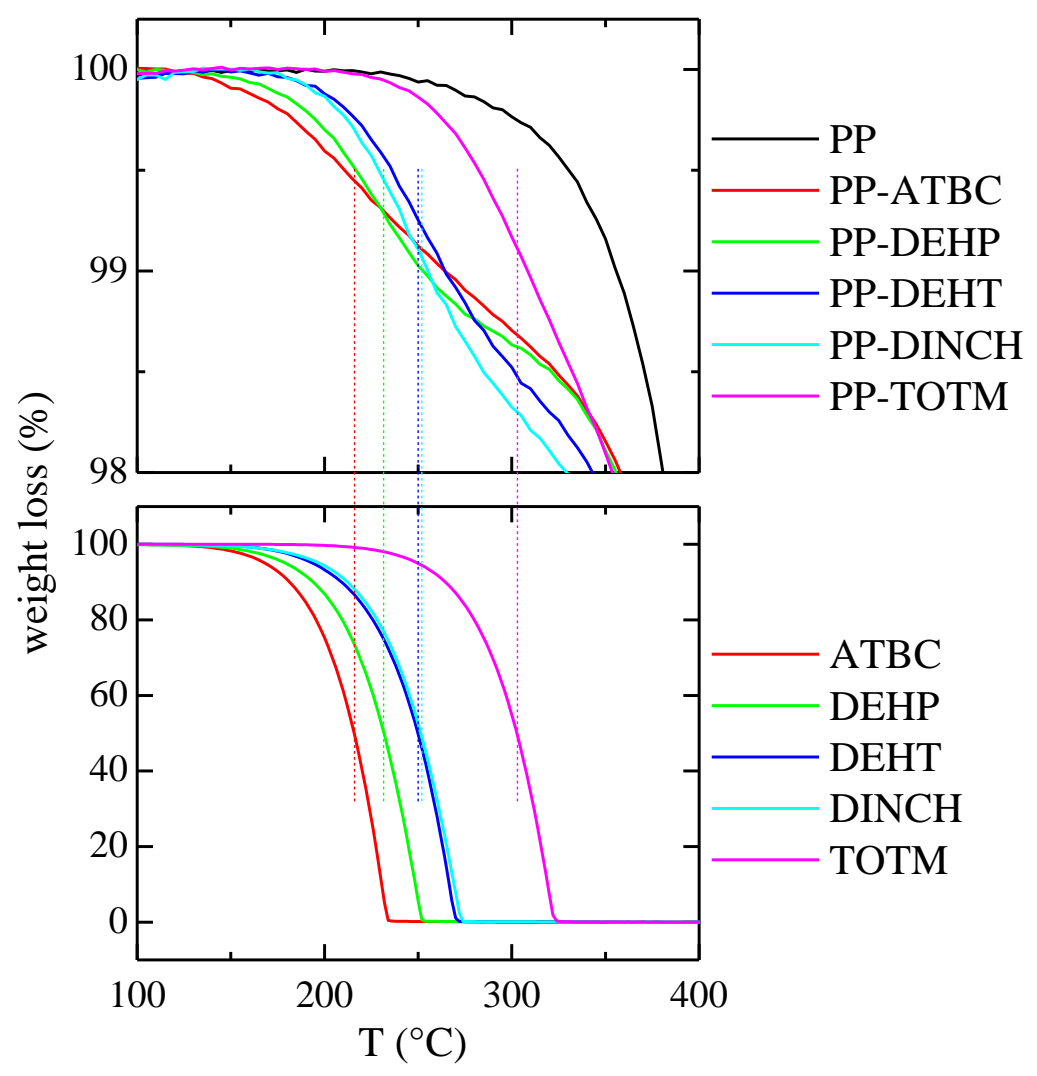

Figure 4. Comparison of the TGA curves of the pure plasticizers (bottom) with those obtained for the iPP-plasticized materials (upper, amplification of Figure 3). 
In order to keep unchanging as much as possible the structure and properties of iPP along the thermo-oxidation process the preservation of the content of antioxidant additive must be of capital importance. Its loss under the experimental conditions might boost the beginning of the iPP degradation, involving a rapid reduction in properties. Therefore, variation of the content of Irgafos 168 within the annealed films has been also quantified. Figure 5 shows that there is not Irgafos 168 left after day 8 in the distinct films of the different iPP based materials except in the PP-DEHP where a $10 \%$ is still observed. Simultaneously, the content in oxidized form of Irgafos 168 is increased with time, as the resultant gas chromatograms revealed. It is reported [25] that this phosphite stabilizer uptakes oxygen from the environment and is oxidized stoichiometrically to the corresponding phosphate. Accordingly, it turns out rather interesting to learn the chemical changes that occur within the IPP chains during the loss of plasticizer and the Irgafos 168 consumption at $95^{\circ} \mathrm{C}$ with increasing degradation time.

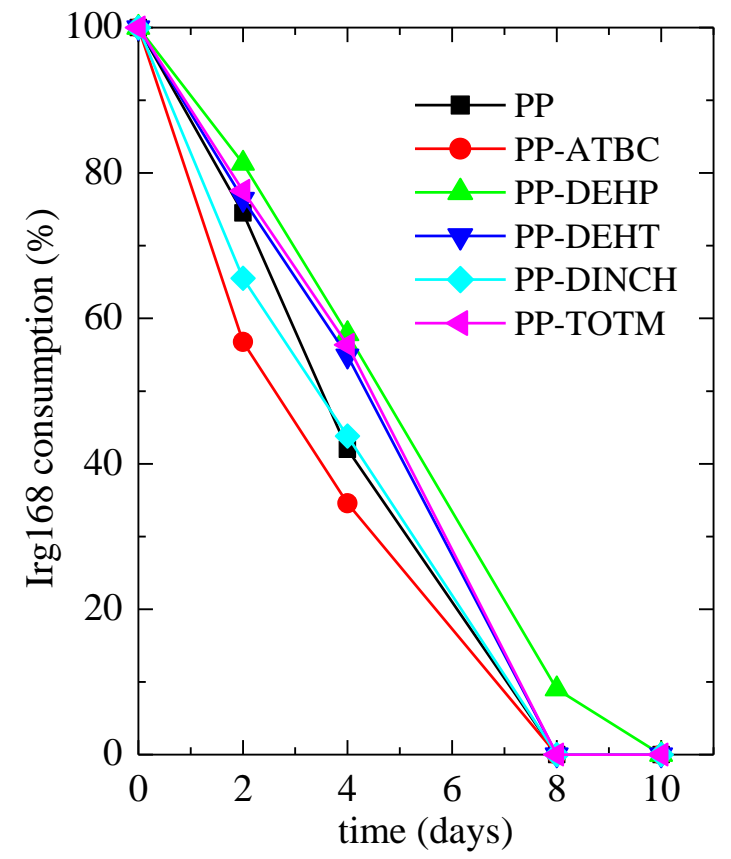

Figure 5. Consumption of Irgafos 168 on thermo-oxidation time at $95^{\circ} \mathrm{C}$.

Figure 6 shows ATR-FTIR spectra for all of the samples evaluated. Development of oxidant species is clearly noticed in the spectra for thermo-oxidation times of 10 days or longer. Chemical changes related to the beginning of iPP degradation have been extensively studied by infrared spectroscopy [26-30]. The appearance of bands in the region between 1700 and $1800 \mathrm{~cm}^{-1}$, ascribed to the formation of carboxyl species, such as acids, esters, ketones or lactones, starts to be observed as degradation is initiated [26-30]. 
Presence of the distinct plasticizers is also identified in the initial films before the thermal treatment (results for day $0, \mathrm{~d} 0$ ) through the FTIR spectra from observation of the specific bands at each additive incorporated. These bands do not overlap with any characteristic one from the pure iPP, although some of them appear in the carbonyl region of degraded iPP. Thus, ATBC shows a unique wide band at $1748 \mathrm{~cm}^{-1}$ related to its ester groups in day 0 . The DEHP is characterized at that time (day 0) by its corresponding ester functionality at $1733 \mathrm{~cm}^{-1}$ together with other small signals at 1072 and 741 $\mathrm{cm}^{-1}$. The specific ester band of DINCH appears at $1736 \mathrm{~cm}^{-1}$ and for DEHT bands are seen at 1726 , 1266 and $731 \mathrm{~cm}^{-1}$. The TOTM, which is the plasticizer with higher molecular weight, exhibits its ester band at $1731 \mathrm{~cm}^{-1}$ (and another two at 1233 and $752 \mathrm{~cm}^{-1}$ ).

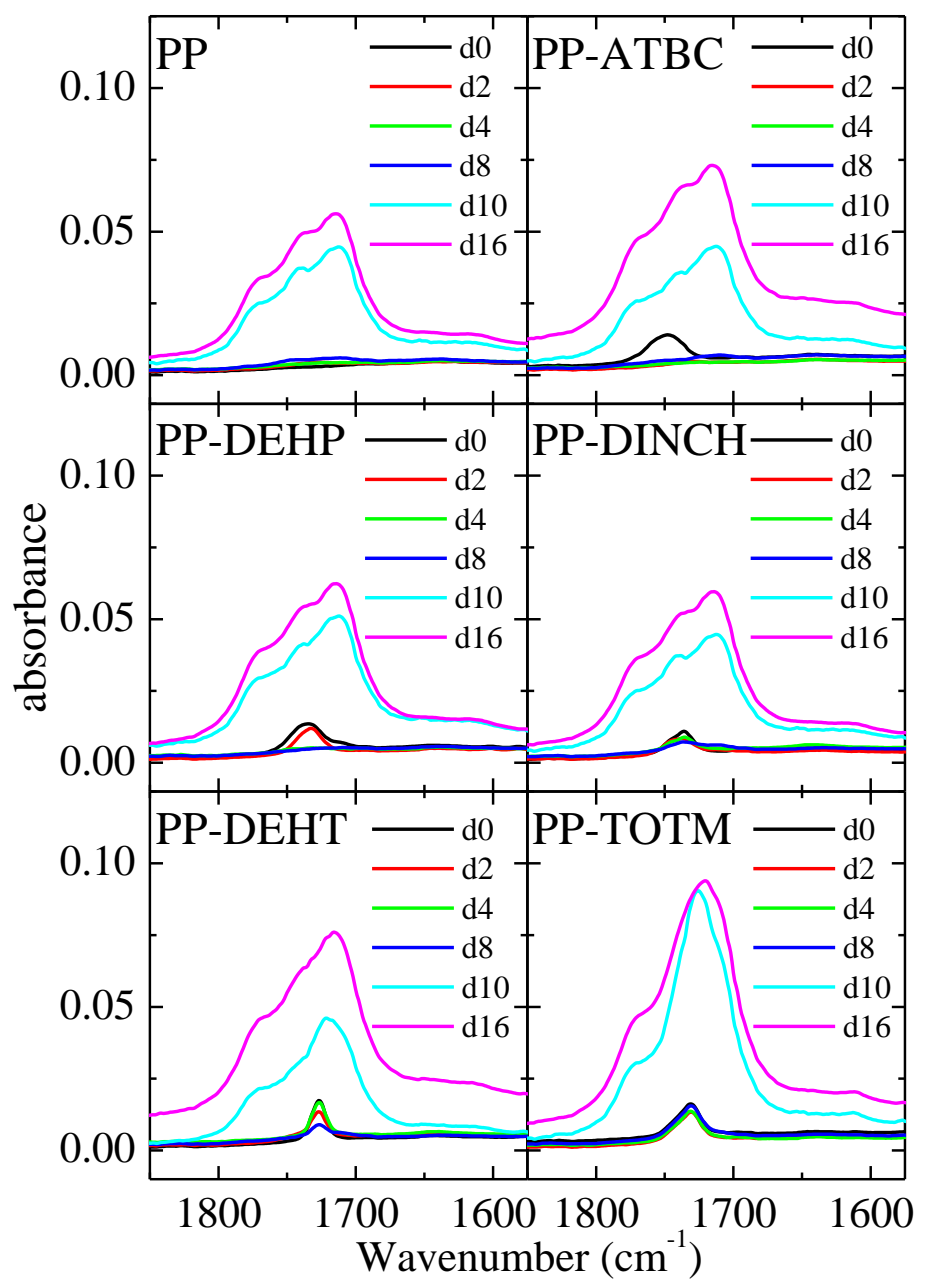

Figure 6. ATR-FTIR spectra for the different samples in the carbonyl region (expanded down to the reference band at $1460 \mathrm{~cm}^{-1}$ ) and for the various thermo-oxidation times at $95{ }^{\circ} \mathrm{C}$.

Figure 6 clearly shows that the wavenumber interval corresponding to the ester group present in the distinct plasticizers is superimposed to the one related to formation of the different oxidative species 
in the iPP. A common feature is observed in every of PP-plasticizer materials: all show at day 0 an ester band, which is characteristic of each plasticizer as just commented, while no band is observed for neat iPP. As the degradation progresses, the plasticizer and the antioxidant additive are lost and those small bands decrease in intensity, even disappearing in some materials. Simultaneously, the appearance of a complex and increasingly intense band arising from coexistence of different oxidant groups is observed as mentioned above for the pristine IPP. The cases of PP-DEHT and PP-TOTM are significantly different. Thus, when observing the spectra at day 16 , it seems that the degradation of iPP is higher in those two materials. However, it has to be considered that these two plasticizers are kept in very significant proportions even after 16 days (around $88 \%$ of TOTM and $22 \%$ of DEHT). Consequently, the ester bands of the remaining plasticizer are added to the ones arising from degradation of iPP. It should be commented that in order to have comparable results, the area of the peaks obtained in the carbonyl region has been normalized taking as reference the band at $1460 \mathrm{~cm}^{-1}$.

Figure 6 proves how important is the presence of Irgafos 168 in the observation of the intense and composite band ascribed to the existence of diverse carbonyl-carboxyl groups. No evidence of this band is seen while antioxidant is present, even when the amount is very little. At longer times, when Irgafos 168 consumption is complete, the multiple bands clearly appear. The global area of all carbonylcarboxyl changes with degradation time, increasing as it is raised. These results are comparable with those reported in other accelerated study under different weathering conditions [31], although there are significant differences by effect of the different plasticizers.

Loss of the plasticizer and consumption of Irgafos 168 at $95^{\circ} \mathrm{C}$ at the distinct thermo-oxidation times have involved changes in the chemical composition of IPP that indicate formation of oxidative species because of beginning of degradation. Their effect on crystalline structure and its phase transitions is important to be understood now.

The first parameter that can be altered by the thermal treatment applied is the molecular weight, since in polymers its variation is very sensitive with the beginning of decomposition processes [29]. Two of these materials have been analyzed for the day $0(\mathrm{~d} 0)$ and $16(\mathrm{~d} 16)$ : the pristine iPP and the PPDINCH. The average values of molecular weight derived from SEC experiments for the pure iPP are 175,000 and 136,000 for $d 0$ and d16, respectively, while they are 166,000 and 153,000 in the PPDINCH for d0 and d16, respectively. It seems that incorporation of the plasticizer allows maintaining rather unchanged the molecular weight during thermal treatment. Consequently, pristine iPP (where only presence of antioxidant was detected) shows a more significant decrease of this parameter. Moreover, a variation in polydispersity has been also seen in the $\mathrm{d} 16$ samples either for the neat iPP or PP-DINCH after treatment at $95^{\circ} \mathrm{C}$ for 16 days. It becomes broader for these d16 specimens in these 
two materials, mainly because of the formation of a significant fraction of a low molecular weight tail. The decay on the average molecular weights points out the existence of chain scission whereas the growth of molecular weight distribution seems to prove that thermo-oxidation does not involve random chain scission. As reported previously in electron beam irradiated metallocene iPP [29], polydispersity should decrease slightly with increasing degradation time if simple scission would take place.

How do these chemical changes and chain length variations affect the crystalline structure at the end of the thermo-oxidation process? In general, isotactic polypropylene can crystallize into different polymorphs by changing microstructural features, crystallization conditions and other factors like incorporation of specific nucleants [32-35]. Thus, three different polymorphic modifications, $\alpha, \beta$ and $\gamma$, all of them sharing a three-fold conformation, have been described together with a phase of intermediate or mesomorphic order obtained by fast quenching [32,34-38]. In addition to these four modifications, a trigonal form has been more recently reported in the case of isotactic copolymers of propylene with high contents of 1-hexene [39-41] or 1-pentene [42,43], in propylene terpolymers with 1pentene and 1-hexene $[44,45]$ as comonomers, and in propylene terpolymers with 1-pentene and 1heptene [46], synthesized all by using metallocene catalysts.

Figure 7 shows the WAXD profiles at room temperature for pristine iPP and the distinct plasticized materials before beginning the thermal treatment, i.e., for the $\mathrm{d} 0$ specimens. All of these patterns exhibit the main reflections characteristic of the monoclinic lattice $[32,33]$. No evidence is seen for the distinctive (117) diffraction ascribed to the orthorhombic cell. This y polymorph has been studied in detail for iPP homopolymers and a close correlation was found between the concentration of defects and the maximum content of the orthorhombic polymorph that the chains could develop [47]. Its presence is then more common in IPP synthesized with metallocenes than with Ziegler-Natta catalysts [48-50]. The absence of this crystalline lattice in the present IPP can be related to the rapid cooling applied from the melt during processing of the diverse films.

Figure 7 also depicts that significant changes are not observed in these WAXD profiles, independently of plasticizer presence and its type. Accordingly, the degree of crystallinity developed does not considerably vary in these initial films. Similarly, the corresponding melting temperatures, estimated from the first melting process in the DSC experiments, also remain rather unchanged, at around $144.5^{\circ} \mathrm{C}$, for all the different materials analyzed. Moreover, the melting enthalpies are also rather similar, with a value of $99 \pm 5 \mathrm{~J} / \mathrm{g}$, meaning that the DSC crystallinity takes an average value of $0.62 \pm 0.03$ 


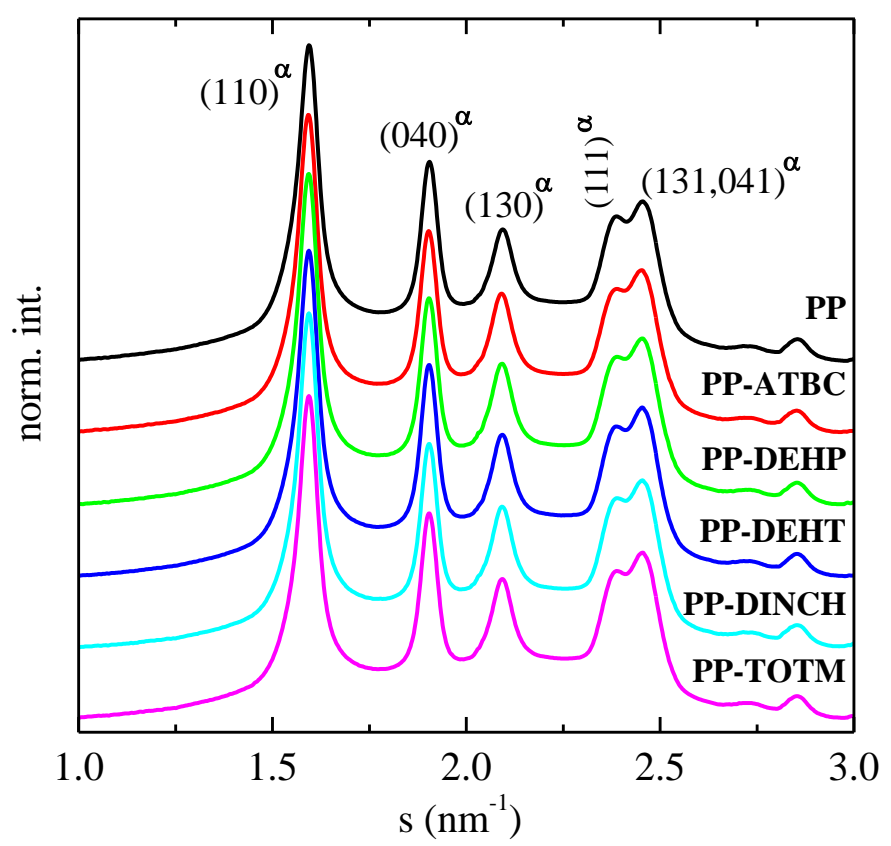

Figure 7. X-ray profiles at room temperature for the pristine iPP and the different original plasticized materials (specimens $\mathrm{d} 0$ ).

Figure 8 displays, however, that once the materials become completely molten, the subsequent crystallization is strongly dependent on either degradation time or the large / small loss of plasticizer (and antioxidant) in the iPP matrix. Before thermo-oxidation, i.e., in the samples labeled as do, crystallization is not practically affected by incorporation of plasticizer and takes place at approximately $113.5^{\circ} \mathrm{C}$, for the pristine iPP and the several plasticized materials. As the thermo-oxidation progresses, crystallization in the neat IPP is first very slightly moved to higher temperatures for the lowest times, while this exothermic process is clearly split into two peaks (at about 112.5 and $105^{\circ} \mathrm{C}$ ) for the longest stay at $95{ }^{\circ} \mathrm{C}$. This feature is also observed in all the distinct plasticized materials, although the degradation time at which these two exothermic events take place depends on the plasticizer used. Incidentally, the effect on the crystallinity is not significant, with values slightly higher than those mentioned above for the first melting of $\mathrm{d} 0$ samples.

The PP-ATBC, PP-DEHP and PP-DINCH materials show the existence of that double peak behavior already at $\mathrm{d} 10$, which is a time shorter than for the neat iPP. Moreover, a unique crystallization process is seen in those three samples for the longest d16 time and its location corresponds to the process that occurs at the lower temperature, i.e., at approximately $106^{\circ} \mathrm{C}$. 


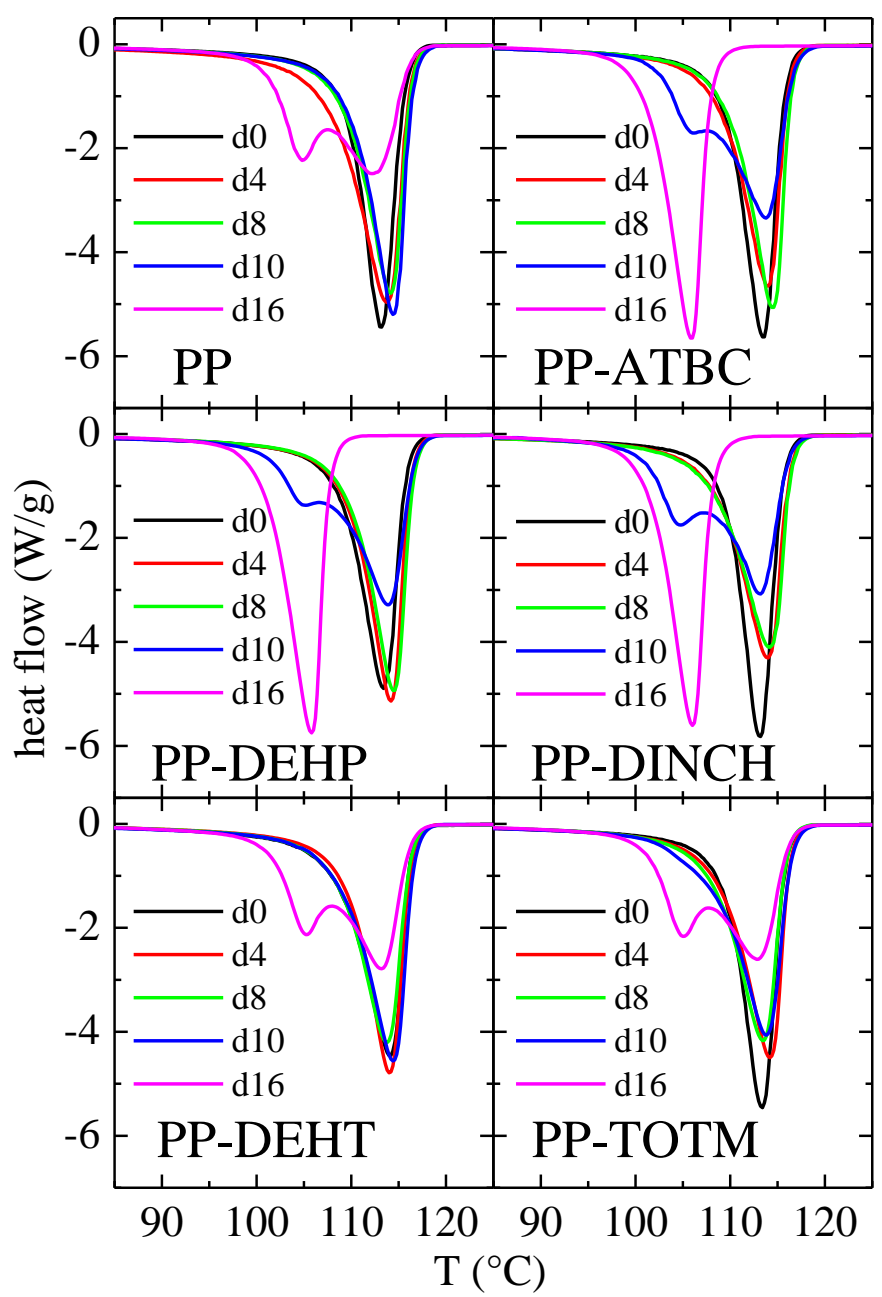

Figure 8. Crystallization curves (at $20^{\circ} \mathrm{C} / \mathrm{min}$ ) from the melt for the distinct materials analyzed after the different degradation times at $95^{\circ} \mathrm{C}$.

On the contrary, the PP-DEHT and PP-TOTM materials behave analogously to pristine iPP, so that a single crystallization process occurs at short times and the splitting is observed for the treatment d16. Why do these differences exist? The results exhibited up to now have indicated similar characteristics except for the effect of degradation in the capability of maintenance or loss of the plasticizers incorporated. In fact, those exhibiting only the low-temperature exotherm at d16 are the PPATBC, PP-DEHP and PP-DINCH materials, i.e., those that lose faster the plasticizer. This trend seems to be delayed in the neat IPP, which does not incorporate any plasticizer, and in the PP-DEHT and PPTOTM, both keeping around $22 \%$ and $88 \%$ of their respective plasticizer amounts after 16 days of thermal treatment. Figure 9 represents the relative area of the crystallization event located at the lower temperature for the highest thermo-oxidation times tested, showing values significantly smaller in these three materials: IPP, PP-DEHT and PP-TOTM, being these latest the plasticized materials with high plasticizer amounts present in the d16 samples (approximately 22\% for DEHT and $88 \%$ for TOTM). 


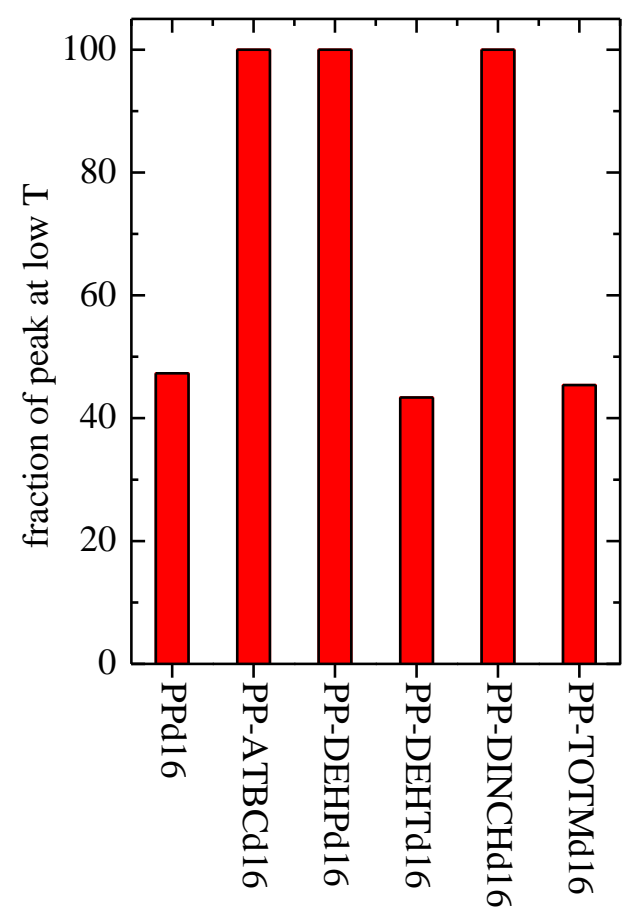

Figure 9. Relative area of the crystallization process appearing at the lowest temperature for the different materials (d16 specimens).

Which is the reason behind this behavior? Presence of a double crystallization process primarily might indicate the development of two populations of crystals with rather different crystallite sizes or formation of two distinct polymorphs. Initial films of the different materials exhibit exclusively the monoclinic crystal lattice with analogous characteristics, including the degree of crystallinity, as depicted in Figure 7. However, all the samples develop a considerable amount of orthorhombic y modification after crystallization from the melt at $20^{\circ} \mathrm{C} / \mathrm{min}$, as observed in Figure 10 , where the (117) diffraction of that modification is clearly observed. But more importantly, there are very significant differences in the amount of $y$ form between $\mathrm{d} 0$ and $\mathrm{d} 16$ specimens, being considerably lower in the degraded samples.

Thus, the upper plot in Figure 10 (d0 samples) shows coexistence of two polymorphs, the a monoclinic and $y$ orthorhombic one. Once the initial monoclinic crystallites (Figure 7) developed along the films processing are molten, those two crystalline lattices can be generated, first of all because the metallocene origin of the iPP and, secondly, because the rate applied in these crystallization experiments $\left(20^{\circ} \mathrm{C} / \mathrm{min}\right)$ is smaller than that used during film processing. Content in the y orthorhombic modification can be tailored by changing either crystallization temperature in isothermal tests or rate in the dynamic experiments, turning out favorable for its formation the crystallization at low rates [51]. 


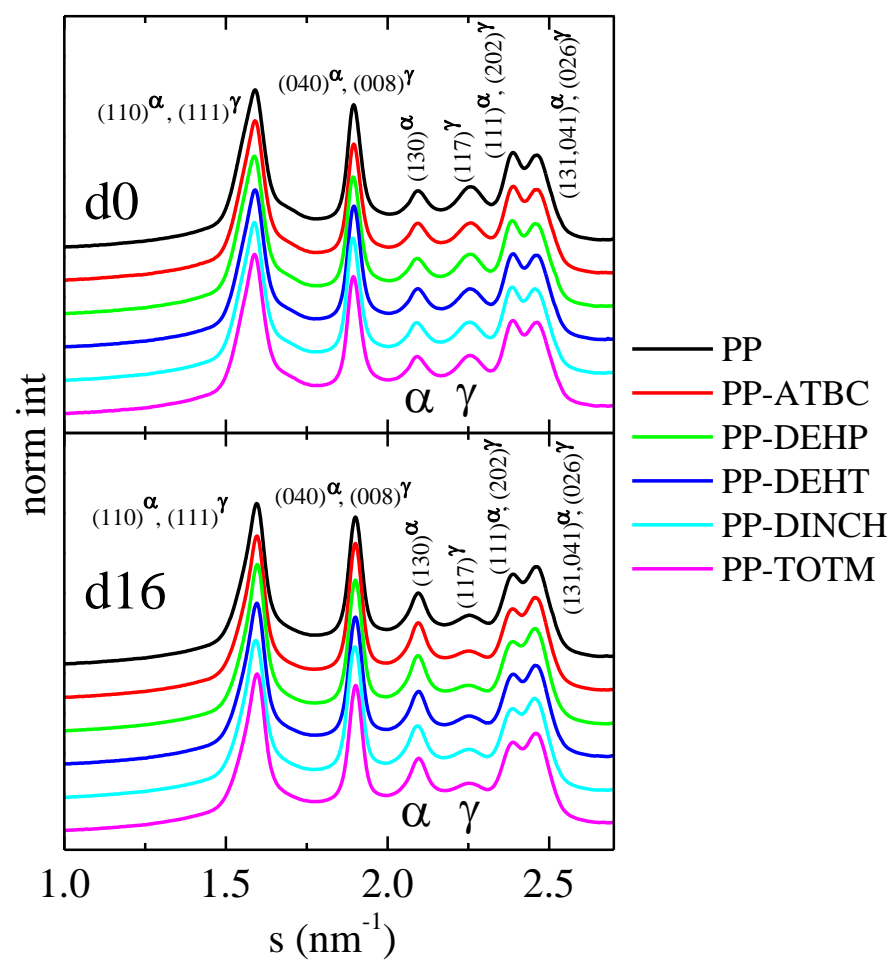

Figure 10. Synchrotron WAXD 1D diffractograms at room temperature after cooling from the melt at 20 ${ }^{\circ} \mathrm{C} / \mathrm{min}$ of the different materials analyzed: upper plot, before thermal treatment, $\mathrm{d} 0$ specimens; and, lower plot, after degradation at $95^{\circ} \mathrm{C}$ for 16 days, d16 samples.

The relative amounts of both crystalline modifications have been assessed from the area ratio of their characteristic reflections: the (130) one located at $s$ of $2.01 \mathrm{~nm}^{-1}$ for monoclinic crystals; and the (117) diffraction at $2.25 \mathrm{~nm}^{-1}$ associated with the $y$ lattice [29,52]. Left plot in Figure 11 shows that the content in the orthorhombic polymorph for the different iPP based materials before degradation is rather significant (around 50\%) despite the fact that crystallization rate used $\left(20^{\circ} \mathrm{C} / \mathrm{min}\right)$ has not been very low.

The lower plot in Figure 10 together with the right representation in Figure 11 shows the important effect that degradation for 16 days exerts in the crystallization capability for all the different materials. Consumption of the antioxidant, formation of oxidative species, changes in the microstructure and/or loss of plasticizer significantly hinder the development of the orthorhombic modification in more than a half. Carbon nuclear magnetic resonance experiments have been carried out in order to achieve supplementary microstructural information on the influence of degradation in the iPP macrochains. The results indicate that degradation involves an increase in the isotacticity of the polymeric chains. Consequently, the lower number of errors in the materials d16 leads to a smaller formation of the $\mathrm{V}$ polymorph [47]. The changes that occur with the degradation time allow rising the length of the regular 
sequences and, consequently, a higher amount of monoclinic crystallites are formed at the expense of the orthorhombic ones.

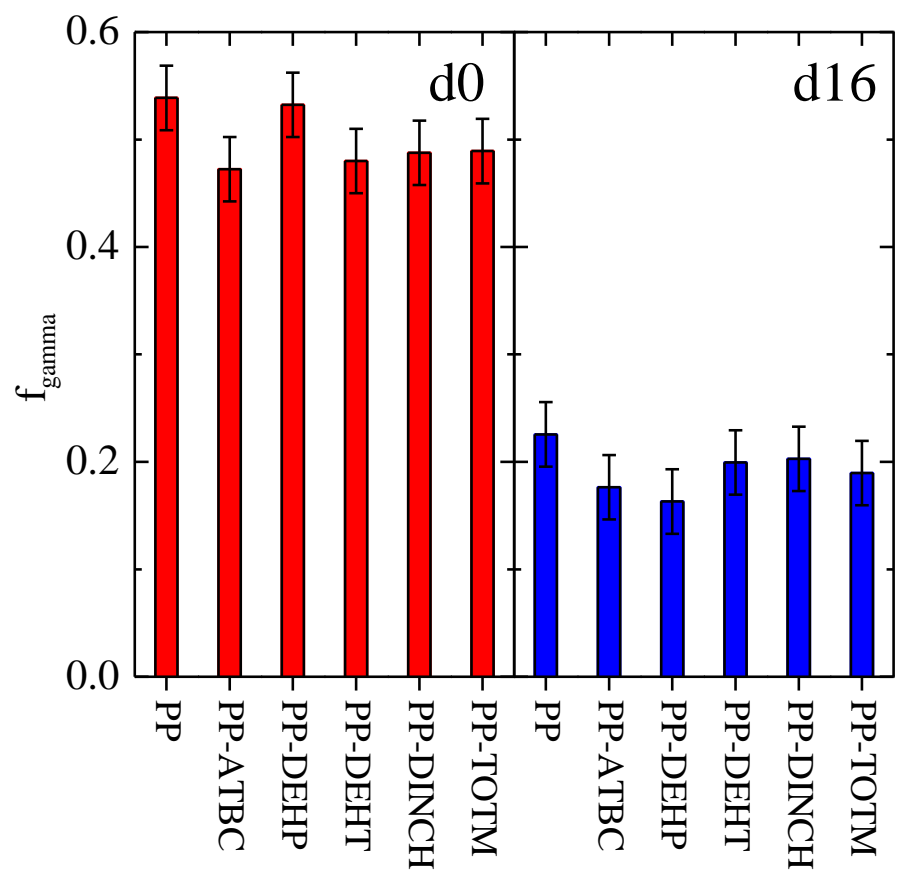

Figure 11. Relative content in the $y$ orthorhombic polymorph estimated by WAXD for the different materials after cooling from the melt at $20^{\circ} \mathrm{C} / \mathrm{min}$ : original ones ( $\mathrm{d} 0$, left) and after 16 days degradation (d16, right).

To understand the cause behind the splitting of crystallization into two exothermic events, realtime variable-temperature WAXD experiments with synchrotron radiation have been performed on cooling under identical conditions than DSC measurements. Results are depicted in Figure 12. Degradation affects not only the formation of orthorhombic lattice but the crystallization process is considerably hampered, as deduced from comparison of the profiles exhibited by PP-d0 and PP-d16. This hindrance is much more noticeable in the PP-DEHP material. Thus, beginning of crystallization is shifted to significantly lower temperatures when comparing the patterns observed in PPDEHP-d0 with those exhibited by PPDEHP-d16. Importantly, the ratio between monoclinic and orthorhombic modifications keeps approximately constant during crystallization for every sample. Microstructural changes derived from degradation leads to a double variation in the crystalline structure: on one hand, formation of orthorhombic crystallites is importantly hindered; and, on the other hand, crystallization is considerably delayed. Both aspects could be associated with the development of a small content of branches during the non-random scission deduced from the reduction of molecular weight and broadening of its distribution, both commented previously. Existence of these lateral chains slows down 
crystallization but could contribute to lengthen isotactic sequences fact that favors preferential formation of monoclinic crystallites.
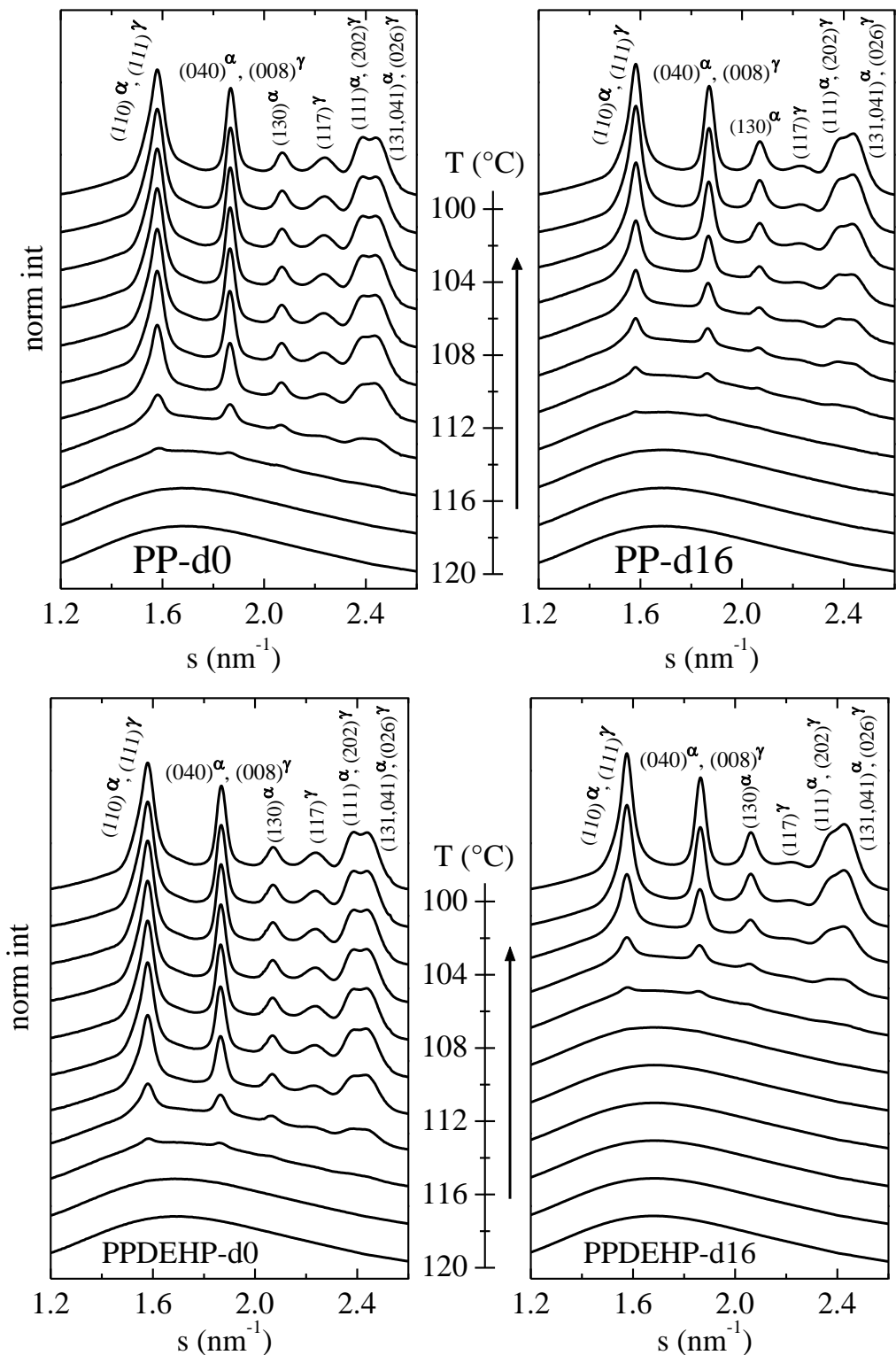

Figure 12. Real-time variable-temperature WAXD diffractograms on cooling from the melt (at $20^{\circ} \mathrm{C} / \mathrm{min}$ ) performed with synchrotron radiation for iPP (upper) and PP-DEHP (lower) at d0 (left) and d16 (right).

For clarity, only the region between 120 and $100{ }^{\circ} \mathrm{C}$ is depicted.

Figure 13 shows the excellent agreement attained in location and shape between the derivative of the WAXD crystalline area and the DSC results for PP (left plots) and PP-DEHP (right plots). In order to determine that WAXD crystalline area, the amorphous halo subtraction has been performed to the Xray experimental profile at each and every single temperature. Result of that subtraction involves 
exclusively the crystalline contribution and, thus, its area can be estimated. The obtainment of the amorphous halo at each temperature has been described previously in detail [19].

These two complementary measurements, derivative of crystalline area and DSC cooling curve, allow deducing crystallization hindrance in addition to difficulty for formation of $y$ crystals.
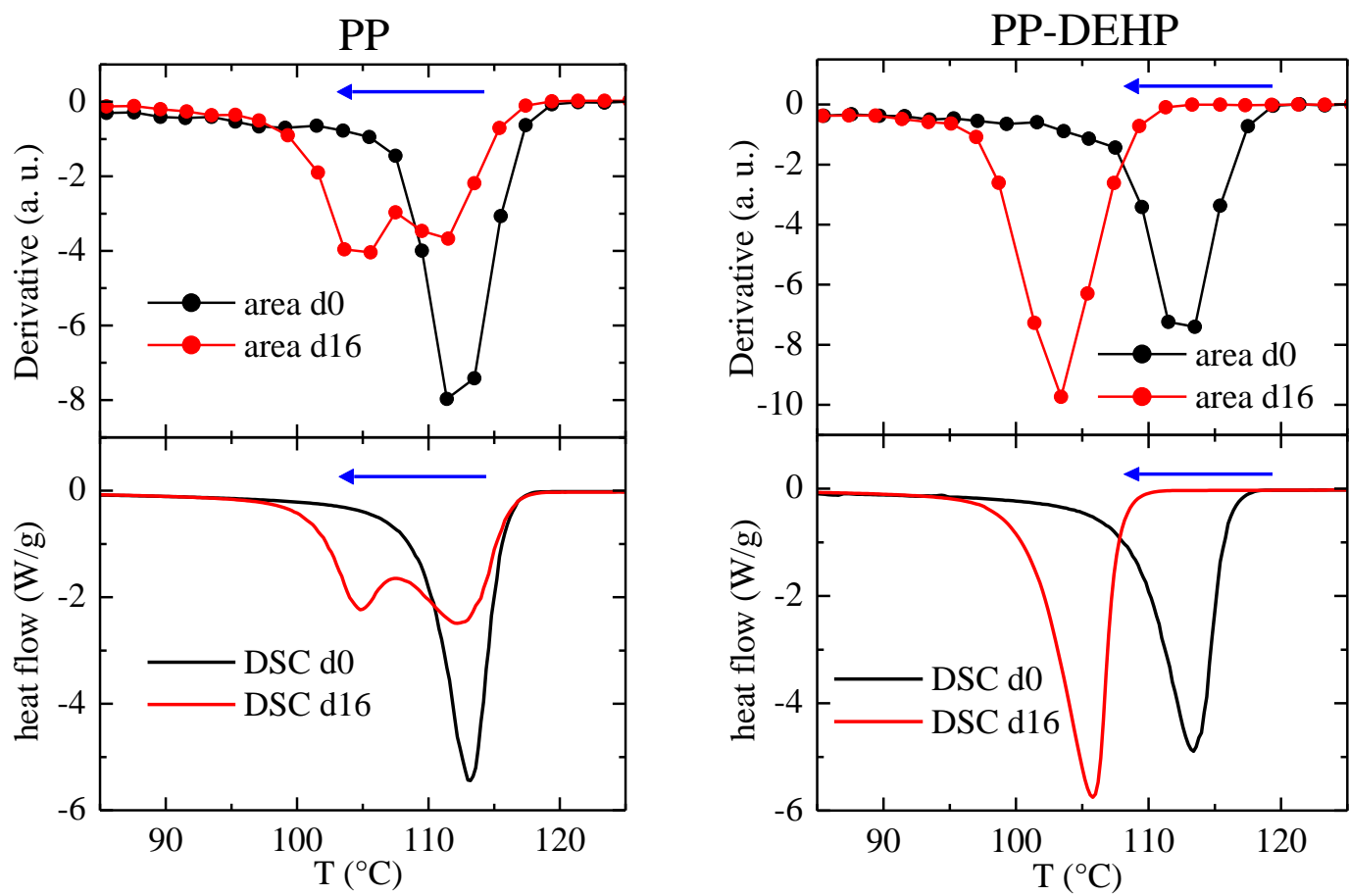

Figure 13. Top plots: Derivatives of the variation with temperature of area of the crystalline diffractions for the PP (left representation) and PP-DEHP (right representation) at d0 and d16 degradation times. Bottom plots: DSC cooling curves for the d0 and d16 specimens for the PP (left representation) and PP. DEHP (right representation).

It is expected that these important changes in crystalline details affect the macroscopic response of the different materials. The characteristics at the surface through profilometry and the mechanical response with the thermo-oxidation time have been checked in some of the materials. Figure 14 shows the results achieved for those materials losing the plasticizer at the fastest and slowest rate, i.e., PP-ATBC and PP-TOTM. The upper plot clearly shows the increase in roughness at the surface of films with the degradation time. In addition, it is undoubtedly noticed that roughness is in PPATBC considerably higher than in PP-TOTM. Loss of the plasticizer leads to the formation within the bulk film of a frame of voids and crazes during degradation. This path is related to the run throughout the film that a specific plasticizer has to perform during its leakage out. Roughness determination has turned out very insightful respect to the degree of plasticizer loss, although it is a superficial 
characteristic and these voids and crazes are located all through the bulk. Consequently, for a given material, roughness changes are observed when the incorporated plasticizer initiates its migration mechanism. Moreover, these variations are also dependent on amount of the plasticizer left in the different materials at a specific degradation time since the material that has lost a higher content becomes rougher.

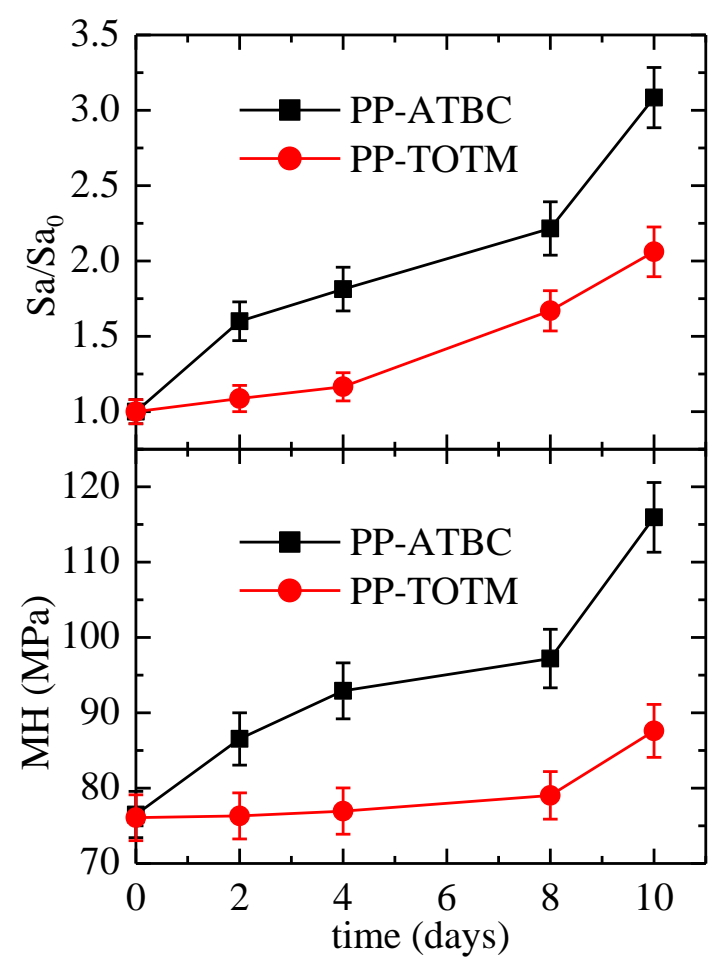

Figure 14. Dependence of normalized average surface roughness (top) and microhardness (bottom) upon degradation time for the PP-ATBC and PP-TOTM materials.

Microhardness (MH) experiments have been selected for estimation of the mechanical behavior of these materials because they are also related to the response at surface. Values obtained at the different thermo-oxidation times are listed in Table 1. The hardness of a material can be defined as a measure of the resistance to a permanent deformation or damage. The deformation of a semicrystalline polymer under the action of the indenter is basically ruled by several effects: an elastic deformation that yields an instant elastic recovery on unloading; a permanent plastic deformation determined by arrangement and structure of crystallites and their connection by tie molecules and entanglements; and a viscoelastic contribution, which is time-dependent during loading with a long delayed recovery after load removal. Therefore, although $\mathrm{MH}$ measurements are ascribed to the superficial mechanical response they also involve a complex combination of other bulk mechanical properties (elastic modulus, 
yield strength, strain hardening, toughness) and a correlation with rigidity modulus is commonly found [21,53-55]. Moreover, microhardness variations with structural parameters can be also expected since mechanical properties are structure-dependent. Accordingly, all the variables that lead to an increase of crystallinity and crystallite sizes $[56,57]$ will provide higher microhardness values.

Table 1. Microhardness $(\mathrm{MH})$ values for the different plasticized materials at the distinct thermooxidation times.

\begin{tabular}{lccccc}
\hline & \multicolumn{5}{c}{ MH (MPa) } \\
\cline { 2 - 6 } samples & \multicolumn{5}{c}{ Thermo-oxidation time (days) } \\
\cline { 2 - 6 } & 0 & 2 & 4 & 8 & 16 \\
\hline PP-ATBC & $80 \forall 4$ & $87 \forall 5$ & $93 \forall 5$ & $97 \forall 5$ & $116 \forall 6$ \\
PP-DEHP & $80 \forall 4$ & $85 \forall 5$ & $92 \forall 5$ & $97 \forall 5$ & $100 \forall 5$ \\
PP-DINCH & $80 \forall 4$ & $83 \forall 5$ & $87 \forall 5$ & $94 \forall 5$ & $98 \forall 5$ \\
PP-DEHT & $80 \forall 4$ & $82 \forall 4$ & $83 \forall 54$ & $89 \forall 5$ & $95 \forall 5$ \\
PP-TOTM & $80 \forall 4$ & $80 \forall 4$ & $81 \forall 4$ & $83 \forall 4$ & $91 \forall 4$ \\
\hline
\end{tabular}

Figure 14 shows a very good agreement between dependence of average superficial roughness and microhardness values on degradation times. Thus, $\mathrm{MH}$ increases as time does and their values are in PP-ATBC superior than in PP-TOTM. Higher MH values mean larger rigidity, but why is PP-ATBC stiffer than PP-TOTM? Mechanical magnitudes are associated, as just mentioned, with structural parameters, such as crystallinity and/or crystal size. Nevertheless, there are not important differences in both magnitudes as deduced from X-ray diffraction and melting temperatures results. The higher values found in PP-ATBC might have relation to the amount of void and craze paths, these being greater than in PP-TOTM because the ATBC plasticizer is completely lost while TOTM at the end of degradation test remains around $88 \%$. Those hollow channels impose residual stresses $[58,59]$ that lead to the increase of mechanical parameters ascribed to rigidity, like microhardness values. Accordingly, the more holes within films there are, either because degradation time increases or a given plasticizer content decreases, the greater the $\mathrm{MH}$ value will be. $\mathrm{MH}$ also rises with time for the rest of the plasticized materials, as deduced from Table 1. Moreover, the smaller is the amount of plasticizer remaining at a given time the greater is the increase in $\mathrm{MH}$. It should be also reminded that a plasticizer is added to increase flexibility within polymers through weakening inter and intramolecular polymeric chains 
interactions. Therefore, higher plasticizer contents remaining in the material will lead to smaller stiffness. Relationships might change in more advanced stages of degradation, when extent in scission reactions is significantly enlarged and reduction in average in molecular weight is more severe.

\section{Conclusions}

A small content of different plasticizers (2 wt.\%) has been added to a metallocene isotactic polypropylene to evaluate their loss rate under severe thermo-oxidative conditions together with the subsequent effects of degradation time on crystalline characteristics, on film surface and on final mechanical performance.

The remaining content for each plasticizer displays important differences with degradation time during their thermo-oxidation at $95{ }^{\circ} \mathrm{C}$ in the distinct iPP based films. Results indicate that PP-TOTM material is the one where plasticizer remains in a very significant content after the 16 days of thermal treatment whereas the ATCB amount is drastically reduced in only 10 hours. Antioxidant consumption takes place simultaneously along degradation and chemical changes occur within the iPP chains, which involve formation of carboxyl-carbonyl species, reduction of average molecular weight and a widening of molecular weight distribution.

All of these changes in the iPP microstructure promoted a delay in the overall crystallization and a hindrance in formation of the orthorhombic crystallites, mostly in the materials with higher plasticizer loss rates. An increase in roughness at the film surface is simultaneously observed with degradation time together with an enlargement of rigidity.

In summary, PP could be considered a friendly matrix compared with PVC and TOTM seems to be a safe candidate as plasticizer to replace the use of the toxic DEHP.

\section{Acknowledgements}

The financial support from project MAT2016-79869-C2-1-P (AEI/FEDER, UE) is greatly acknowledged. The synchrotron experiments were performed at beamline BL11-NCD at ALBA Synchrotron Light Facility with the collaboration of ALBA staff. Authors are grateful for the funding received to perform these measurements.

\section{References}

[1] Y. Haishima, R. Matsuda, Y. Hayashi, C. Hasegawa, T. Yagami, T. Tsuchiya, Risk assessment of di(2ethylhexyl)phthalate released from PVC blood circuits during hemodialysis and pump-oxygenation therapy, International Journal of Pharmaceutics 274 (2004) 119-129. 
[2] D. Koniecki, R. Wang, R.P. Moody, J.P. Zhu, Phthalates in cosmetic and personal care products: Concentrations and possible dermal exposure, Environmental Research 111 (2011) 329-336.

[3] F. Chiellini, M. Ferri, A. Morelli, L. Dipaola, G. Latini, Perspectives on alternatives to phthalate plasticized poly(vinyl chloride) in medical devices applications, Prog. Polym. Sci. 38 (2013) 1067-1088.

[4] A. Prasannan, J.J. Jhu, C.J. Wu, S.Y. Lin, H.C. Tsai, Evaluation of the temperature and molecular weight dependent migration of di(2-ethylhexyl) phthalate from isotactic polypropylene composites, Reactive \& Functional Polymers 113 (2017) 70-76.

[5] K.L. Howdeshell, A.K. Hotchkiss, L.E. Gray, Cumulative effects of antiandrogenic chemical mixtures and their relevance to human health risk assessment, International Journal of Hygiene and Environmental Health 220 (2017) 179-188.

[6] A.D. LaFleur, K.A. Schug, A review of separation methods for the determination of estrogens and plastics-derived estrogen mimics from aqueous systems, Anal. Chim. Acta 696 (2011) 6-26.

[7] H.Q. Fang, J. Wang, R.A. Lynch, Migration of di(2-ethylhexyl)phthalate (DEHP) and di-n-butylphthalate (DBP) from polypropylene food containers, Food Control 73 (2017) 1298-1302.

[8] X.L. Cao, Phthalate Esters in Foods: Sources, Occurrence, and Analytical Methods, Comprehensive Reviews in Food Science and Food Safety 9 (2010) 21-43.

[9] L. Bernard, R. Cueff, C. Breysse, B. Decaudin, V. Sautou, G. Armed Study, Migrability of PVC plasticizers from medical devices into a simulant of infused solutions, International Journal of Pharmaceutics 485 (2015) 341-347.

[10] H. Fromme, A. Schutze, T. Lahrz, M. Kraft, L. Fernbacher, S. Siewering, R. Burkardt, S. Dietrich, H.M. Koch, W. Volkel, Non-phthalate plasticizers in German daycare centers and human biomonitoring of DINCH metabolites in children attending the centers (LUPE 3), International Journal of Hygiene and Environmental Health 219 (2016) 33-39.

[11] L. Correia-Sa, A. Schutze, S. Norberto, C. Calhau, V.F. Domingues, H.M. Koch, Exposure of Portuguese children to the novel non-phthalate plasticizer di-(iso-nonyl)-cyclohexane-1,2-dicarboxylate (DINCH), Environment International 102 (2017) 79-86.

[12] P. Gimeno, S. Thomas, C. Bousquet, A.F. Maggio, C. Civade, C. Brenier, P.A. Bonnet, Identification and quantification of 14 phthalates and 5 non-phthalate plasticizers in PVC medical devices by GC-MS, Journal of Chromatography BAnalytical Technologies in the Biomedical and Life Sciences 949 (2014) 99-108.

[13] D. Bourdeaux, M. Yessaad, P. Chennell, V. Larbre, T. Eljezi, L. Bernard, V. Sautou, A.S. Grp, Analysis of PVC plasticizers in medical devices and infused solutions by GC-MS, Journal of Pharmaceutical and Biomedical Analysis 118 (2016) 206-213.

[14] T. Eljezi, P. Pinta, D. Richard, J. Pinguet, J.M. Chezal, M.C. Chagnon, V. Sautou, G. Grimandi, E. Moreau, In vitro cytotoxic effects of DEHP-alternative plasticizers and their primary metabolites on a L929 cell line, Chemosphere 173 (2017) 452-459.

[15] M. Erceg, T. Kovacic, I. Klaric, Thermal degradation of poly(3-hydroxybutyrate) plasticized with acetyl tributyl citrate, Polym. Degrad. Stab. 90 (2005) 313-318.

[16] M.P. Arrieta, J. Lopez, D. Lopez, J.M. Kenny, L. Peponi, Effect of chitosan and catechin addition on the structural, thermal, mechanical and disintegration properties of plasticized electrospun PLA-PHB biocomposites, Polym. Degrad. Stab. 132 (2016) 145-156.

[17] A. Greco, A. Maffezzoli, Cardanol derivatives as innovative bio-plasticizers for poly-(lactic acid), Polym. Degrad. Stab. 132 (2016) 213-219.

[18] R. Krache, R. Benavente, J.M. López-Majada, J.M. Perena, M.L. Cerrada, E. Pérez, Competition between a, $\beta$, and y polymorphs in a $\beta$-nucleated metallocenic isotactic polypropylene, Macromolecules 40 (2007) 6871-6878.

[19] E. Pérez, M.L. Cerrada, R. Benavente, J.M. Gómez-Elvira, Enhancing the formation of the new trigonal polymorph in isotactic propene-1-pentene copolymers: Determination of the X-ray crystallinity, Macromol. Res. 19 (2011) 1179-1185.

[20] ASME: Surface texture (surface roughness, waviness, and lay), B46.1-2002 standard. American Society of Mechanical and Engineering, New York (2002).

[21] F.J.B. Calleja, Microhardness relating to crystalline polymers, Adv. Polym. Sci. 66 (1985) 117-148.

[22] E.J. Dziwinski, B.P. Pozniak, J. Lach, GC/MS and ESI/MS identification of the new generation plasticizers - cis and trans isomers of some 1,2-cyclohexane dicarboxylic acid di(n-and isononyl) esters, Polym. Test. 62 (2017) 319-324.

[23] K. Kambia, T. Dine, R. Azar, B. Gressier, M. Luyckx, C. Brunet, Comparative study of the leachability of di(2-ethylhexyl) phthalate and tri(2-ethylhexyl) trimellitate from haemodialysis tubing, International Journal of Pharmaceutics 229 (2001) $139-146$.

[24] Q. Wang, W. Wu, Y.F. Tang, J.J. Bian, S.W. Zhu, Thermal Degradation Kinetics of Plasticized Poly (Vinyl Chloride) with Six Different Plasticizers, Journal of Macromolecular Science Part B-Physics 56 (2017) 420-434.

[25] J. Pospísil, Chemical and photochemical behaviour of phenolic antioxidants in polymer stabilization: a state of the art report, part II, Polym. Degrad. Stab. 39 (1993) 103-115.

[26] G. Geuskens, M.S. Kabamba, Photooxidation of polymers-Part V: A new chain scission mechanism in polyolefins, Polym. Degrad. Stab. 4 (1982) 69-76.

[27] P. Delprat, X. Duteurtre, J.L. Gardette, Photooxidation of unstabilized and HALS-stabilized polyphasic ethylenepropylene polymers, Polym. Degrad. Stab. 50 (1995) 1-12.

[28] J.L. Philippart, C. Sinturel, R. Arnaud, J.L. Gardette, Influence of the exposure parameters on the mechanism of photooxidation of polypropylene, Polym. Degrad. Stab. 64 (1999) 213-225. 
[29] M.L. Cerrada, E. Pérez, R. Benavente, J. Ressia, C. Sarmoria, E.M. Vallés, Gamma polymorph and branching formation as inductors of resistance to electron beam irradiation in metallocene isotactic polypropylene, Polym. Degrad. Stab. 95 (2010) 462-469.

[30] C. Rouillon, P.O. Bussiere, E. Desnoux, S. Collin, C. Vial, S. Therias, J.L. Gardette, Is carbonyl index a quantitative probe to monitor polypropylene photodegradation?, Polym. Degrad. Stab. 128 (2016) 200-208.

[31] A. Niemczyk, K. Dziubek, M. Grzymek, K. Czaja, Accelerated laboratory weathering of polypropylene composites filled with synthetic silicon-based compounds, Polym. Degrad. Stab. 161 (2019) 30-38.

[32] A. Turner-Jones, J.M. Aizlewood, D.R. Beckett, Crystalline forms of isotactic polypropylene, Makromol. Chem. 75 (1964) 134-158.

[33] S. Brückner, S.V. Meille, V. Petraccone, B. Pirozzi, Polymorphism in isotactic polypropylene, Prog. Polym. Sci. 16 (1991) 361-404.

[34] J. Varga, Supermolecular structure of isotactic polypropylene, J. Mater. Sci. 27 (1992) 2557-2579.

[35] B. Lotz, J.C. Wittmann, A.J. Lovinger, Structure and morphology of poly(propylenes): A molecular analysis, Polymer 37 (1996) 4979-4992.

[36] J. Grebowicz, S.F. Lau, B. Wunderlich, The thermal properties of polypropylene, J. Polym. Sci., Polym. Symp. 71 (1984) 19-37.

[37] M.J. Polo-Corpa, R. Benavente, T. Velilla, R. Quijada, E. Pérez, M.L. Cerrada, Development of the mesomorphic phase in isotactic propene/higher a-olefin copolymers at intermediate comonomer content and its effect on properties, Eur. Polym. J. 46 (2010) 1345-1354.

[38] E. Pérez, J.M. Gómez-Elvira, R. Benavente, M.L. Cerrada, Tailoring the formation rate of the mesophase in random propylene-co-1-pentene copolymers, Macromolecules 45 (2012) 6481-6490.

[39] B. Poon, M. Rogunova, A. Hiltner, E. Baer, S.P. Chum, A. Galeski, E. Piorkowska, Structure and properties of homogeneous copolymers of propylene and 1-hexene, Macromolecules 38 (2005) 1232-1243.

[40] C. De Rosa, S. Dello lacono, F. Auriemma, E. Ciaccia, L. Resconi, Crystal structure of isotactic propylene-hexene copolymers: The trigonal form of isotactic polypropylene, Macromolecules 39 (2006) 6098-6109.

[41] M.L. Cerrada, M.J. Polo-Corpa, R. Benavente, E. Pérez, T. Velilla, R. Quijada, Formation of the new trigonal polymorph in iPP - 1-hexene copolymers. Competition with the mesomorphic phase, Macromolecules 42 (2009) 702-708.

[42] C. De Rosa, O.R. de Ballesteros, F. Auriemma, M.R. Di Caprio, Crystal Structure of the Trigonal Form of Isotactic Propylene-Pentene Copolymers: An Example of the Principle of Entropy-Density Driven Phase Formation in Polymers, Macromolecules 45 (2012) 2749-2763.

[43] A. García-Peñas, J.M. Gómez-Elvira, V. Lorenzo, E. Pérez, M.L. Cerrada, Unprecedented dependence of stiffness parameters and crystallinity on comonomer content in rapidly cooled propylene-co-1-pentene copolymers, Polymer 130 (2017) 17-25.

[44] L. Boragno, P. Stagnaro, F. Forlini, F. Azzurri, G.C. Alfonso, The trigonal form of i-PP in random C3/C5/C6 terpolymers, Polymer 54 (2013) 1656-1662.

[45] A. García-Peñas, J.M. Gõmez-Elvira, E. Pérez, M.L. Cerrada, Isotactic poly(propylene-co-1-pentene-co-1-hexene) terpolymers: Synthesis, molecular characterization, and evidence of the trigonal polymorph, Journal of Polymer Science, Part A: Polymer Chemistry 51 (2013) 3251-3259.

[46] A. García-Peñas, J.M. Gómez-Elvira, R. Barranco-García, E. Pérez, M.L. Cerrada, Trigonal $\delta$ form as a tool for tuning mechanical behavior in poly(propylene-co-1-pentene-co-1-heptene) terpolymers, Polymer 99 (2016) 112-121.

[47] R.G. Alamo, M.H. Kim, M.J. Galante, J.R. Isasi, L. Mandelkern, Structural and kinetic factors governing the formation of the gamma polymorph of isotactic polypropylene, Macromolecules 32 (1999) 4050-4064.

[48] F. Auriemma, C. De Rosa, Crystallization of metallocene-made isotactic polypropylene: Disordered modifications intermediate between the alpha and gamma forms, Macromolecules 35 (2002) 9057-9068.

[49] O. Prieto, J.M. Pereña, R. Benavente, E. Pérez, M.L. Cerrada, Viscoelastic relaxation mechanisms of conventional polypropylene toughened by a plastomer, Journal of Polymer Science, Part B: Polymer Physics 41 (2003) 1878-1888.

[50] R.G. Alamo, J.A. Blanco, P.K. Agarwal, J.C. Randall, Crystallization rates of matched fractions of MgCl2-supported Ziegler-Natta and metallocene isotactic poly(propylene)s. 1. The role of chain microstructure, Macromolecules 36 (2003) $1559-1571$.

[51] C. De Rosa, F. Auriemma, M. Paolillo, L. Resconi, I. Camurati, Crystallization behavior and mechanical properties of regiodefective, highly stereoregular isotactic polypropylene: Effect of regiodefects versus stereodefects and influence of the molecular mass, Macromolecules 38 (2005) 9143-9154.

[52] R. Barranco-García, J.M. López-Majada, J.C. Martínez, J.M. Gómez-Elvira, E. Pérez, M.L. Cerrada, Confinement of iPP crystallites within mesoporous SBA-15 channels in extruded iPP-SBA-15 nanocomposites studied by Small Angle X-ray scattering, Microporous and Mesoporous Materials 272 (2018) 209-216.

[53] M.L. Cerrada, J.L. de la Fuente, M. Fernandez-Garcia, E.L. Madruga, Viscoelastic and mechanical properties of poly(butyl acrylate-g-styrene) copolymers, Polymer 42 (2001) 4647-4655.

[54] M.L. Cerrada, R. Benavente, E. Pérez, Crystalline structure and viscoelastic behavior in composites of a metallocenic ethylene-1-octene copolymer and glass fiber, Macromol. Chem. Phys. 203 (2002) 718-726.

[55] M.L. Cerrada, E. Pérez, J.P. Lourenço, J.M. Campos, M. Rosário Ribeiro, Hybrid HDPE/MCM-41 nanocomposites: Crystalline structure and viscoelastic behaviour, Microporous and Mesoporous Materials 130 (2010) 215-223. 
[56] C. Fonseca, J. Pereña, R. Benavente, M.L. Cerrada, A. Bello, E. Pérez, Microhardness and thermal study of the annealing effects in vinyl alcohol-ethylene copolymers, Polymer 36 (1995) 1887-1892.

[57] J. Arranz-Andrés, J.L. Guevara, T. Velilla, R. Quijada, R. Benavente, E. Pérez, M.L. Cerrada, Syndiotactic polypropylene and its copolymers with alpha-olefins. Effect of composition and length of comonomer, Polymer 46 (2005) 12287-12297.

[58] L.C.E. Struik: Internal Stresses, Dimensional Instabilities and Molecular Orientations in Plastics John Wiley \& Sons Ltd, Chichester, U.K. (1990).

[59] M.L. Cerrada, J.M. Pereña, R. Benavente, E. Pérez, Viscoelastic processes in vinyl alcohol-ethylene copolymers. Influence of composition and thermal treatment, Polymer 41 (2000) 6655-6661. 